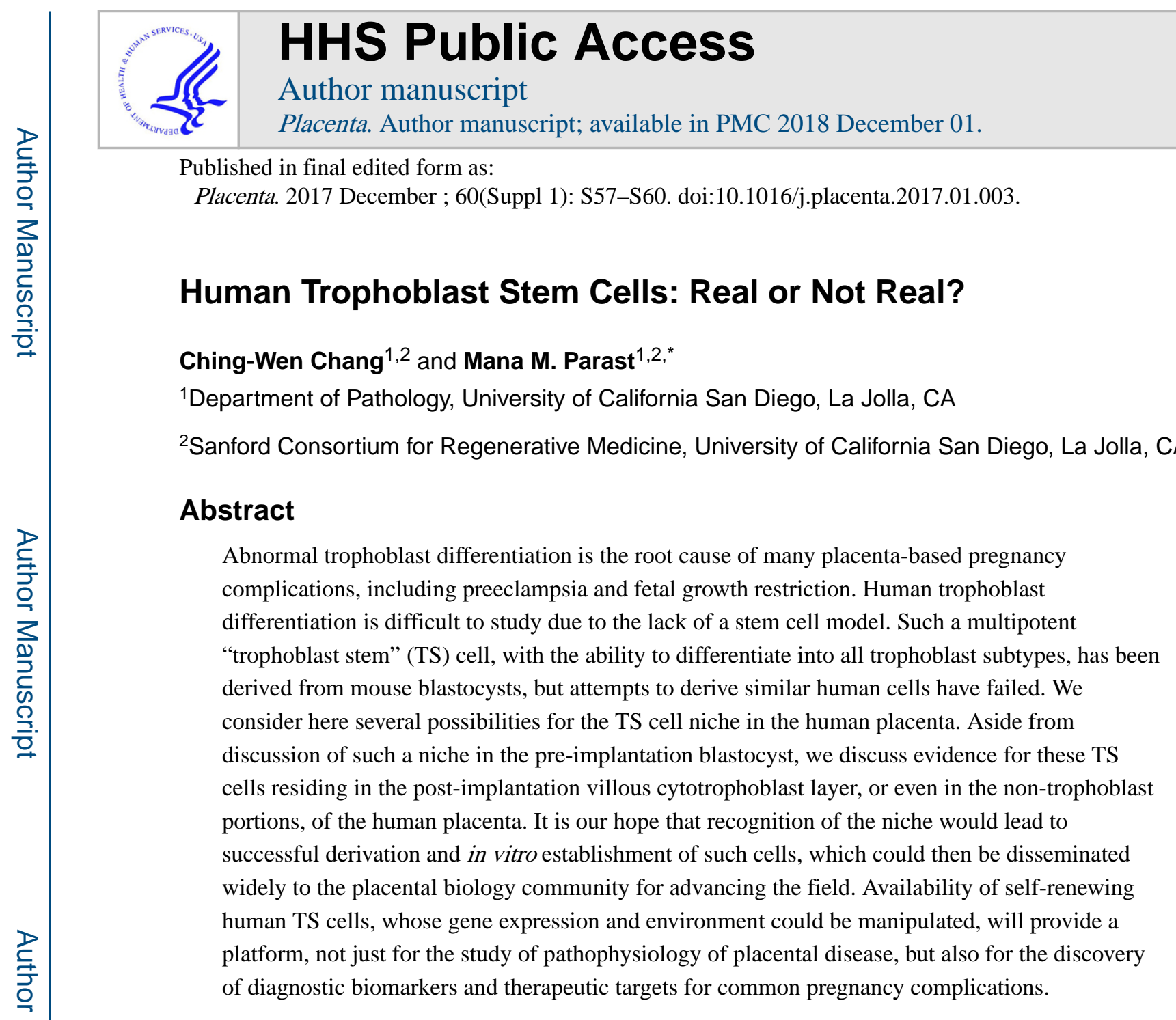

\title{
Introduction
}

The concept of a stem cell niche was first suggested by Schofield in 1978 to describe the bone-marrow microenvironment of hematopoietic stem cells (HSCs) [1]. It was initially defined as the site of residence of stem cells in a particular anatomical tissue; however, over the past 30 years, this definition has evolved and now includes a particular microenvironment which protects stem cells, providing them with growth factors and extracellular matrix components to maintain their stemness. Knowledge of the niche has led to derivation of various types of stem cells, including embryonic stem cells (ESCs) and tissue-specific stem cells (such as HSCs, and mesenchymal stem cells/MSCs), all of which

Corresponding Author: Mana M. Parast, MD PhD, Sanford Consortium for Regenerative Medicine, Department of Pathology, University of California San Diego, 9500 Gilman Drive, MC 0695, La Jolla, CA 92093, USA. Tel: (858)-534-8631, Fax: (858)-246-1586, mparast@ucsd.edu.

Publisher's Disclaimer: This is a PDF file of an unedited manuscript that has been accepted for publication. As a service to our customers we are providing this early version of the manuscript. The manuscript will undergo copyediting, typesetting, and review of the resulting proof before it is published in its final citable form. Please note that during the production process errors may be discovered which could affect the content, and all legal disclaimers that apply to the journal pertain.

The authors have no conflict of interest to report. 
have proven useful as in vitro models for studying molecular mechanisms of lineage specification and organ development [2-4].

The human placenta has been dubbed the "least understood organ" [5]; unfortunately, this statement also applies to the stem cells which contribute to this organ, namely, trophoblast stem cells (TSCs) which give rise to the epithelial components of the placenta. Knowledge of the TSC niche in the polar trophectoderm of the mouse embryo led to their successful derivation almost 20 years ago [6]. However, isolation of similar cells from the human blastocyst has remained a challenge [7, 8], due, at least in part, to the lack of knowledge regarding the TSC niche during early human development. Studies have pointed to both various gestational ages and various compartments, where such human TSC might exist [714]. In this review, we will discuss the various proposed niches for human TSC (Figure 1), highlighting the many questions that remain and the areas which require further study.

\section{Trophectoderm of the preimplantation blastocyst}

Trophoblast lineage specification begins with the formation of the blastocyst, where inner cell mass (ICM), the precursor to all embryonic tissues as well as extraembryonic endoderm and mesoderm, separates from an outer layer of cells called trophectoderm (TE), which are thought to give rise to all trophoblast (extraembryonic ectoderm) subtypes after implantation [7]. TSC were first isolated from TE outgrowths of mouse blastocysts, using a combination of fibroblast growth factor 4 (FGF4) and mouse embryonic fibroblast (MEFs) [6]; the latter secrete TGF-beta/activin as the required active components, and thus can be replaced by media conditioned by the feeders [15]. Mouse TSCs are characterized by expression of transcription factors, CDX2, ELF5, and EOMES, all of which are required for maintenance of this lineage in vivo $[11,12]$. In the absence of feeders and FGF4, the cells lose the above markers, and begin to differentiate [6]. Recent studies of human embryos, however, have shown that, of the above factors, only CDX2 is specifically expressed in the pre-implantation TE [9, 14]. In addition, unlike the mouse, human TE initially co-expressed OCT4 along with CDX2, with OCT4 being confined to the ICM only in later stage blastocysts ( 6 days post fertilization) [14]. More recently, Blakeley et al. have taken these findings further using single-cell RNAseq, showing that key mouse TE-associated genes, including Elf5, Eomes and $I d 2$, are completely absent in human TE; conversely, genes highly expressed in human TE, including CLDN10, TRIML1 and PLAC8, were absent in mouse TE [9]. Interestingly, of these, CLDN10, a tight junction component, may participate in TSC niche formation, as establishment of apicobasal cell polarity is a critical step in TE formation in mice [16, 17]; also, a related family member, CLDN11, is required for establishment of the spermatogonial stem cell niche in mice [18]. Further study is needed to unravel functions of these genes in human TE, with respect to both trophoblast lineage specification and/or TSC maintenance.

To further study early lineage commitment in the human embryo, two groups recently recapitulated this process in vitro, showing that early embryonic development can take place in the absence of any maternal tissues [19,20]. They observed the blastocysts to always attach on the side of the polar TE, the area where trophoblast is nearest the inner cell mass; this is distinct from the same process in mouse, where mural TE initiate attachment [21]. At this stage in the human embryo, TE was best defined by nuclear expression of GATA3, 
although a variable amount of CDX2 expression was also present. Following attachment, the embryo flattened and the GATA $3^{+}$TE acquired strong filamentous CK7 staining, followed, after a few days, by appearance of multinucleated cells and induction of human chorionic gonadotropin-beta (hCG $\beta$ ) expression in the expanding TE. Taken together, these results indicate that polar TE is critical during implantation and that trophoblast differentiation, at least in these early stages, can be induced within the embryo itself, without input from maternal tissues $[19,20]$.

Recently, derivation of embryonic stem cell (hESC) lines have been reported from single blastomeres of 8-to-10-cell human embryos; these hESC lines appear to have a unique gene expression and DNA methylation profile, indicating a higher competence toward trophoblast differentiation [22]. However, due to the early nature of the embryonic stage used for their derivation, they cannot be widely distributed for study [22]. Attempts to derive TSC from human blastocyst-stage embryos, based on culture conditions used for mouse TSC derivation or variations thereof, have been unsuccessful [23]. A comparative study of FGF receptors has recently revealed that FGFR2, the main FGF receptor expressed in the mouse blastocyst, is not expressed in the human blastocyst. Interestingly, and similar to ELF5, FGFR2 does appear to be expressed in the post-implantation cytotrophoblast [23]. Based on these latter observations, it has been proposed that, more likely, the human TSC niche may reside in the post-implantation placenta [23].

\section{Postimplantation chorionic villi}

Following implantation, placental villous development rapidly progresses from invagination of proliferating cytotrophoblast (primary villi), to invasion of these structures by mesenchymal cells (secondary villi), and subsequent formation of primitive fetal blood vessels within them (tertiary villi) by the fourth week of gestation [24, 25]. At this stage, two distinct trophoblast subpopulations are observed: a proliferative mononuclear cytotrophoblast (CTB) shell which is immediately adjacent to the villous mesenchyme, and a multinucleated syncytiotrophoblast (STB) which abuts the maternal vascular space (Figure 1). Continuous proliferation of the CTB shell at points of contact with the uterine decidua leads to formation of a third trophoblast subpopulation, the invasive extravillous trophoblast (EVT) [24]. In these regions of anchoring columns, there is a progression of differentiation from a proliferative villous CTB, to a proliferative "proximal column" EVT, to a nonproliferative "distal column" EVT, finally into fully differentiated invasive EVT (Figure 1). The latter include at least two subtypes, based on their localization: interstitial EVT which invade decidua singly or in groups, and endovascular EVT, which invade and remodel maternal spiral arterioles [24, 25]. Along this differentiation pathway, markers of CTB (p63, EGFR) are lost, and those of EVT (HLAG, MelCAM) are gained [24-26]. During this differentiation, an elegant integrin switching is also observed, with loss of ITGA6, and gain of ITGA5 and ITGA1 [27-29].

The primary proposed TSC niche within these early post-implantation villi is the CTB layer, where, aside from p63 [26], a subset of cells have been shown to co-express CDX2 [30] and ELF5 [13]. These cells have been proposed as TSC, based purely on comparative marker expression in mouse TSC, and the rapid loss of this population by the end of the first 
trimester, after which CTB differentiation into $\mathrm{HLA}_{-\mathrm{G}^{+}}$EVT becomes more limited [31]. In addition, villous CTB have also been shown to express FGFR2, the same receptor expressed on mouse TSC, and even proliferate in response to FGF4, in context of the floating villous explant model (i.e. with their underlying mesenchyme intact) [10]. However, primary isolated villous CTB, either as a whole or in part, have yet to be successfully passaged in vitro continuously.

Many epithelial stem cell populations contain "transiently amplifying" progenitor cells, cells defined as committed progenitors, able to expand the progenitor pool in tissues as needed [32]. In the human placenta, the villous CTB layer has been proposed to contain such progenitor populations. In fact, as early as 8 weeks gestation, there is evidence for two populations of CTB progenitors-one that gives rise to STB, and another that gives rise to EVT-defined by different survival charactertistics in the context of the villous explant [33]. It is possible that a bona fide TSC, residing in early (5-8 week gestation) placenta, gives rise in late first trimester to these two distinct progenitor cell populations. A recent study by Haider et al. [34] supports this latter hypothesis, with the identification of a NOTCH1 ${ }^{+}$ villous CTB subpopulation which give rise exclusively to EVT.

Another characteristic of stem cells, the ability to extrude the fluorescent dye Hoechst, has been used to isolate a "side population" of cells from amongst villous CTB [35]. Based on their gene expression profile, the side population cells were more closely related to CTB than EVT, and their proportion did not change significantly between 6 and 12 weeks of gestation [35]. Interestingly, extracellular matrix (ECM)-related genes were significantly enriched within these side population cells [35], indicating that the ECM likely plays a crucial role for establishment and maintenance of this potential stem cell niche. Additional studies are necessary to determine if these side population cells are truly multipotent TSC.

\section{Putative TSC in the non-trophoblast (mesenchymal) portions of placenta}

Finally, the non-trophoblast portion of the chorion has also been proposed as a niche for TSC (Figure 1) [8]. By using a combination of FGF and inhibitors of the activin/nodal pathway, Genbacev et al. were able to isolate and maintain a putative TSC from the chorionic mesenchyme of first and second trimester placentae [8]. This finding is deemed controversial, as these cells are likely of extraembryonic mesoderm (ICM) origin, where all trophoblast are thought to be derived from TE. Nevertheless, these ITGA4 ${ }^{+}$cells seemed to have the ability to differentiate into both STB and EVT, although it was not clear whether they first underwent a CTB precursor phase; in fact, in subsequent studies, they seem to primarily differentiate into $\mathrm{HLAG}^{+}$EVT [36]. In addition, based on their gene expression profile, they appear to have characteristics of both embryonic stem cells and trophoblast $[8$, 36]. However, similar to "TSC"-like embryonic stem cells derived from single human blastomeres [22], the properties of these cells remain to be independently confirmed.

\section{Conclusions and perspectives}

While multiple niches have been described for putative human trophoblast stem/progenitor cells, the bulk of the data point to villous tissue in the early gestation placenta as the most 
likely niche for such cells. Of course, it is highly likely that other compartments house progenitor cells which can give rise to a more limited repertoire of trophoblast subtypes (i.e. CTB in second trimester through term gestation, continue to proliferate and contribute to the STB layer). It is also possible that later gestation placental tissue retains a small but significant subpopulation of true "TSC," which, under specific conditions of damage/stress, and along with signals from the mesenchymal compartment, are able to expand and regenerate functional placental tissue.

Much work remains to test the above hypotheses. While the isolation of primary CTB from various gestation human placentae can be done relatively routinely, variable access to early gestation tissues and our inability to maintain these cells in a proliferative state present the two most significant limitations to the study of human trophoblast differentiation and placental development. A more detailed evaluation of cell types within the human placenta, both during early gestation and in various placental compartments (chorionic villi, chorion, and basal plate), is required in order to understand the niche(s) for TSC and other trophoblast progenitor cells, before we are able to establish such cells in continuous culture. Finally, much work on the human placenta is done by isolated groups/laboratories; significantly more coordination and collaborative effort is required between groups which focus on human placental biology, to standardize nomenclature and phenotypic definitions of trophoblast subpopulations, cell isolation procedures, as well as culture conditions, in order to truly advance this field.

While primary CTB remain the gold standard, human pluripotent stem cells (hPSCs, referring to both embryonic stem cells/hESCs and induced pluripotent stem cells/iPSCs) have also been successfully used to study human trophoblast differentiation [37, 38]. Our own work has recently led to development of a "two-step" protocol, which uses defined culture conditions to produce a uniform population of CDX+/p63+/EGFR+CTB "stem-like" cells, which can be replated and further differentiated into STB- and EVT-like cells [30]. The advantage of these cells is the ability to model both normal and abnormal trophoblast differentiation, using iPSCs derived from individuals/placentae with diverse pregnancy outcomes. In addition, these cells could provide a platform for screening potential drug therapies aimed at placenta-based pregnancy disorders such as preeclampsia and fetal growth restriction. At the same time, application of similar methodology for derivation of iPSC has recently led to derivation of "iTSC"- conversion of mouse fibroblasts to trophoblast stem cells using defined factors $[39,40]$. Although the latter technology has yet to be extended to derivation of similar human cells, there is much hope that such advances in regenerative medicine can also be applied to placental biology, providing ever more sophisticated in vitro models for the study of this crucial human organ, which in turn would serve as platforms for screening of potential therapeutics aimed at improving placental function.

\section{Acknowledgments}

This work was supported by funds from a CIRM Physician-Scientist Award (RN3-06396) and NIH/NICHD (R01HD071100). 


\section{References}

1. Schofield R. The relationship between the spleen colony-forming cell and the haemopoietic stem cell. Blood Cells. 1978; 4(1-2):7-25. [PubMed: 747780]

2. Trounson A. A rapidly evolving revolution in stem cell biology and medicine. Reprod Biomed Online. 2013; 27(6):756-764. [PubMed: 24125943]

3. Bigas A, Waskow C. Blood stem cells: from beginning to end. Development. 2016; 143(19):3429_ 3433. [PubMed: 27702782]

4. Keating A. Mesenchymal stromal cells: new directions. Cell Stem Cell. 2012; 10(6):709-716. [PubMed: 22704511]

5. Guttmacher AE, Maddox YT, Spong CY. The Human Placenta Project: placental structure, development, and function in real time. Placenta. 2014; 35(5):303-304. [PubMed: 24661567]

6. Tanaka S, Kunath T, Hadjantonakis AK, Nagy A, Rossant J. Promotion of trophoblast stem cell proliferation by FGF4. Science. 1998; 282(5396):2072-2075. [PubMed: 9851926]

7. Rossant J. Stem cells and lineage development in the mammalian blastocyst. Reprod Fertil Dev. 2007; 19(1):111-118. [PubMed: 17389140]

8. Genbacev O, Donne M, Kapidzic M, Gormley M, Lamb J, Gilmore J, Larocque N, Goldfien G, Zdravkovic T, McMaster MT, Fisher SJ. Establishment of human trophoblast progenitor cell lines from the chorion. Stem Cells. 2011; 29(9):1427-1436. [PubMed: 21755573]

9. Blakeley P, Fogarty NM, Del Valle I, Wamaitha SE, Hu TX, Elder K, Snell P, Christie L, Robson P, Niakan KK. Defining the three cell lineages of the human blastocyst by single-cell RNA-seq. Development. 2015; 142(18):3151-3165. [PubMed: 26293300]

10. Baczyk D, Dunk C, Huppertz B, Maxwell C, Reister F, Giannoulias D, Kingdom JC. Bi-potential behaviour of cytotrophoblasts in first trimester chorionic villi. Placenta. 2006; 27(4-5):367-374. [PubMed: 15950280]

11. John R, Hemberger M. A placenta for life. Reprod Biomed Online. 2012; 25(1):5-11. [PubMed: 22578825]

12. Roberts RM, Fisher SJ. Trophoblast stem cells. Biol Reprod. 2011; 84(3):412-421. [PubMed: 21106963]

13. Hemberger M, Udayashankar R, Tesar P, Moore H, Burton GJ. ELF5-enforced transcriptional networks define an epigenetically regulated trophoblast stem cell compartment in the human placenta. Hum Mol Genet. 2010; 19(12):2456-2467. [PubMed: 20354077]

14. Niakan KK, Eggan K. Analysis of human embryos from zygote to blastocyst reveals distinct gene expression patterns relative to the mouse. Dev Biol. 2013; 375(1):54-64. [PubMed: 23261930]

15. Erlebacher A, Price KA, Glimcher LH. Maintenance of mouse trophoblast stem cell proliferation by TGF-beta/activin. Dev Biol. 2004; 275(1):158-169. [PubMed: 15464579]

16. Alarcon VB. Cell polarity regulator PARD6B is essential for trophectoderm formation in the preimplantation mouse embryo. Biol Reprod. 2010; 83(3):347-358. [PubMed: 20505164]

17. Marikawa Y, Alarcon VB. Establishment of trophectoderm and inner cell mass lineages in the mouse embryo. Mol Reprod Dev. 2009; 76(11):1019-1032. [PubMed: 19479991]

18. Gow A, Southwood CM, Li JS, Pariali M, Riordan GP, Brodie SE, Danias J, Bronstein JM, Kachar B, Lazzarini RA. CNS myelin and sertoli cell tight junction strands are absent in Osp/claudin-11 null mice. Cell. 1999; 99(6):649-659. [PubMed: 10612400]

19. Deglincerti A, Croft GF, Pietila LN, Zernicka-Goetz M, Siggia ED, Brivanlou AH. Selforganization of the in vitro attached human embryo. Nature. 2016; 533(7602):251-254. [PubMed: 27144363]

20. Shahbazi MN, Jedrusik A, Vuoristo S, Recher G, Hupalowska A, Bolton V, Fogarty NM, Campbell A, Devito LG, Ilic D, Khalaf Y, Niakan KK, Fishel S, Zernicka-Goetz M. Self-organization of the human embryo in the absence of maternal tissues. Nat Cell Biol. 2016; 18(6):700-708. [PubMed: 27144686]

21. Lindenberg S, Hyttel P, Sjøgren A, Greve T. A comparative study of attachment of human, bovine and mouse blastocysts to uterine epithelial monolayer. Hum Reprod. 1989; 4(4):446-456.

[PubMed: 2745676] 
22. Zdravkovic T, Nazor KL, Larocque N, Gormley M, Donne M, Hunkapillar N, Giritharan G, Bernstein HS, Wei G, Hebrok M, Zeng X, Genbacev O, Mattis A, McMaster MT, Krtolica A, Valbuena D, Simón C, Laurent LC, Loring JF, Fisher SJ. Human stem cells from single blastomeres reveal pathways of embryonic or trophoblast fate specification. Development. 2015; 142(23):4010-4025. [PubMed: 26483210]

23. Kunath T, Yamanaka Y, Detmar J, MacPhee D, Caniggia I, Rossant J, Jurisicova A. Developmental differences in the expression of FGF receptors between human and mouse embryos. Placenta. 2014; 35(12):1079-1088. [PubMed: 25443433]

24. James JL, Carter AM, Chamley LW. Human placentation from nidation to 5 weeks of gestation. Part I: What do we know about formative placental development following implantation? Placenta. 2012; 33(5):327-334. [PubMed: 22374510]

25. Benirschke, K., Burton, GJ., Kaufmann, P. Pathology of the human placenta. Sixth. Berlin Heidelberg: Springer-Verlag; 2012.

26. Lee Y, Kim KR, McKeon F, Yang A, Boyd TK, Crum CP, Parast MM. A unifying concept of trophoblastic differentiation and malignancy defined by biomarker expression. Hum Pathol. 2007; 38(7):1003-1013. [PubMed: 17397906]

27. Damsky CH, Fitzgerald ML, Fisher SJ. Distribution patterns of extracellular matrix components and adhesion receptors are intricately modulated during first trimester cytotrophoblast differentiation along the invasive pathway, in vivo. J Clin Invest. 1992; 89(1):210-222. [PubMed: 1370295]

28. Damsky CH, Librach C, Lim KH, Fitzgerald ML, McMaster MT, Janatpour M, Zhou Y, Logan SK, Fisher SJ. Integrin switching regulates normal trophoblast invasion. Development. 1994; 120(12): 3657-3666. [PubMed: 7529679]

29. Zhou Y, Damsky CH, Chiu K, Roberts JM, Fisher SJ. Preeclampsia is associated with abnormal expression of adhesion molecules by invasive cytotrophoblasts. J Clin Invest. 1993; 91(3):950 960. [PubMed: 7680671]

30. Horii M, Li Y, Wakeland AK, Pizzo DP, Nelson KK, Sabatini K, Laurent LC, Liu Y, Parast MM. Human pluripotent stem cells as a model of trophoblast differentiation in both normal development and disease. Proc Natl Acad Sci U S A. 2016; 113(27):E3882-E3891. [PubMed: 27325764]

31. McMaster MT, Librach CL, Zhou Y, Lim KH, Janatpour MJ, DeMars R, Kovats S, Damsky C, Fisher SJ. Human placental HLA-G expression is restricted to differentiated cytotrophoblasts. J Immunol. 1995; 154(8):3771-3778. [PubMed: 7706718]

32. Blanpain C, Horsley V, Fuchs E. Epithelial stem cells: turning over new leaves. Cell. 2007; 128(3): 445-458. [PubMed: 17289566]

33. James JL, Stone PR, Chamley LW. Cytotrophoblast differentiation in the first trimester of pregnancy: evidence for separate progenitors of extravillous trophoblasts and syncytiotrophoblast. Reproduction. 2005; 130(1):95-103. [PubMed: 15985635]

34. Haider S, Meinhardt G, Saleh L, Fiala C, Pollheimer J, Knöfler M. Notch1 controls development of the extravillous trophoblast lineage in the human placenta. Proc Natl Acad Sci U S A. 2016; 113(48):E7710-E7719. [PubMed: 27849611]

35. James JL, Hurley DG, Gamage TK, Zhang T, Vather R, Pantham P, Murthi P, Chamley LW. Isolation and characterisation of a novel trophoblast side-population from first trimester placentae. Reproduction. 2015; 150(5):449-462. [PubMed: 26248480]

36. Genbacev O, Larocque N, Ona K, Prakobphol A, Garrido-Gomez T, Kapidzic M, Bárcena A, Gormley M, Fisher SJ. Integrin alpha4-positive human trophoblast progenitors: functional characterization and transcriptional regulation. Hum Reprod. 2016; 31(6):1300-1314. [PubMed: 27083540]

37. Golos TG, Giakoumopoulos M, Gerami-Naini B. Review: Trophoblast differentiation from human embryonic stem cells. Placenta. 2013; 34(Suppl):S56-S61. [PubMed: 23261342]

38. Li Y, Parast MM. BMP4 regulation of human trophoblast development. Int J Dev Biol. 2014; 58(24):239-246. [PubMed: 25023690]

39. Benchetrit H, Herman S, van Wietmarschen N, Wu T, Makedonski K, Maoz N, Yom Tov N, Stave D, Lasry R, Zayat V, Xiao A, Lansdorp PM, Sebban S, Buganim Y. Extensive Nuclear 
Reprogramming Underlies Lineage Conversion into Functional Trophoblast Stem-like Cells. Cell Stem Cell. 2015; 17(5):543-556. [PubMed: 26412562]

40. Kubaczka C, Senner CE, Cierlitza M, Araúzo-Bravo MJ, Kuckenberg P, Peitz M, Hemberger M, Schorle H. Direct Induction of Trophoblast Stem Cells from Murine Fibroblasts. Cell Stem Cell. 2015; 17(5):557-568. [PubMed: 26412560] 


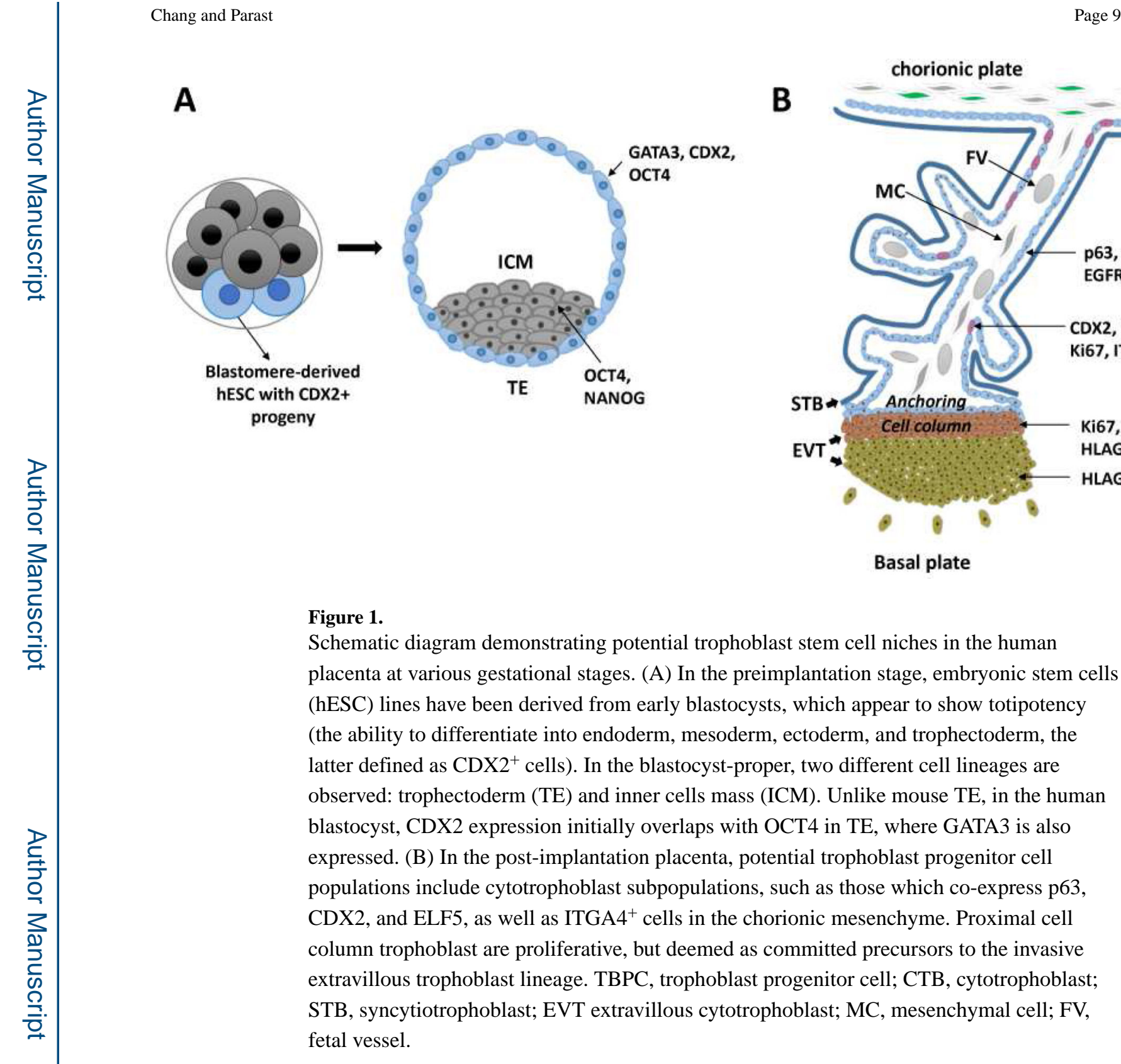

Placenta. Author manuscript; available in PMC 2018 December 01. 